\title{
The Leading Role of Industry in The Nakhchivan Autonomous Republic
}

\author{
Alem M. Baghirov \\ Correspondence: Alem M. Baghirov, Babek mehellesi, Nakhchivan Private University, Nakhchivan, Nakhchivan \\ Autonomous Republic, AZ 7000, Azerbaijan. Tel: 994-50-335-2500. E-mail: a.baghirov@mail.ru
}

Received: February 20, 2012

Accepted: September 25, 2012

Online Published: October 15, 2012

doi:10.5539/ijef.v4n11p210

URL: http://dx.doi.org/10.5539/ijef.v4n11p210

\begin{abstract}
It is shown that the natural condition of the Nakhchivan Autonomous Republic, its geographical position, geopolitical situation, rich natural resources, existence of enough manpower, high level personnel potential, the existing social and production infrastructure create objective atmosphere in rapid development of the industrial fields. The development inclinations of the industry and its features in the Nakhchivan Autonomous Republic are analyzed, creation of new industrial establishment opportunities on the basis of local raw material, ways of its financial maintenance strengthening and perspective growth directions are stated. It is also indicated that the model of development of economy, in particular, industry in the example of the Nakhchivan Autonomous Republic, Azerbaijan can be applied for the remote regions which are exclaves or locations with difficult access to mainland due to geographical (high mountains, remote islands) or climatic (tundra, permanently frozen polar areas) features.
\end{abstract}

Keywords: Nakhchivan Autonomous Republic, market economy, industry, local raw material, investment

\section{Introduction}

The scientific objective or the essential idea behind the presented research work devoted to the investigation of the economy of the Nakhchivan Autonomous Republic which is the integral part of the Republic of Azerbaijan is the concept that regions, which are remote from mainland of the country have their own, specific difficulties and advantages in development of the economy of the region and it is possible to provide the leading role of the industry at the expense of the advantages of the geographical position, natural condition and rich natural resources, existence of enough manpower, high level personnel potential, the existing social and production infrastructure of the region. By remote, we mean not only exclaves (like the Nakhchivan Autonomous Republic, Azerbaijan or the Kaliningrad Region, Russia) but also locations with difficult access to mainland due to geographical (high mountains, remote islands) or climatic (tundra, permanently frozen polar areas) features.

The end of the 20th century long has entered history as a period having fundamental changes of great importance in all political and social directions of Azerbaijan. It bases on the desire state independence achievement of Azerbaijan and passing to the market economy system.

The Nakhchivan Autonomous Republic as a part of the Republic of Azerbaijan also faced with all round crises for valid reasons after gaining the independence of Azerbaijan, the collapse of national economy and before existed division system of labour, loss of sale markets, sharp decrease of industry in all fields of economy and as a result of which it ended with complete stop of major production activity of industrial establishment.

Heydar Aliyev's returning to Nakhchivan in 1990 and his election as a deputy to the parliaments of the Republic Azerbaijan and the Nakhchivan Autonomous Republic by people's will and at last caused gradual healthy and strong public-political stability after his election to the position of the chairman of the Supreme Majlis of the Nakhchivan Autonomous Republic.

When Heydar Aliyev was elected as the President of the Republic of Azerbaijan a gradual progress in industry became an obvious matter in Azerbaijan wholly, as well as in Nakhchivan Autonomous Republic and a great deal of wide scale reforms were held in the field of industry as well as in other sectors of economy.

Today the development of economy in the Republic of Azerbaijan is held due to special state programs. According to "The State Program on social-economic development of regions" (for 2004-2008) upon the decree was signed on February 11, 2004 by Ilham Aliyev, the President of the Republic of Azerbaijan new industrial fields were established in the Nakhchivan Autonomous Republic and industrial output began to increase dynamically. 
During 2004-2008 years 147 industrial establishments were created in the Nakhchivan Autonomous Republic or some of them were reestablished on the bases of new technology.

As a logical continuation of the State Program "Social-economic development State Program of the regions for 2009-2013 of the Republic of Azerbaijan" was confirmed by the decree №80 upon 14 April, 2009 the President of the Republic of Azerbaijan. Along with widening the output of industry and agriculture of the Nakhchivan Autonomous Republic plan of measures consisting of twelve items were determined.

All these stated matters: complex analysis of the problems connected with the development of industry in the Nakhchivan Autonomous Republic, its perspective development and territory forming improvement, joining of the autonomous republic industry to the world economy system, putting forward offers and recommendations in the direction of food safety provision are turned objective necessity.

A number of monographs, books were devoted to the investigation of the economy, in particular, industry of the Nakhchivan Autonomous Republic. The ways of economic development and development features of different branches of economy of the Nakhchivan Autonomous Republic was investigated by N. Ahmadov (N. Ahmadov, 2005; N. Ahmadov, 2008) and other authors. More reliable information on the economy of the Nakhchivan Autonomous Republic can also be found in encyclopaedies devoted to the Nakhchivan Autonomous Republic (Nakhchivan encyclopaedia, 2002; Nakhchivan encyclopaedia, 2005, 1st volume; Nakhchivan encyclopaedia, 2005 , 2nd volume ). However in the presented work we talk about the leading role of industry of the Nakhchivan Autonomous Republic and discuss the model of development of economy, in particular, industry in the example of the Nakhchivan Autonomous Republic that can be applied for the remote regions which are exclaves or locations with difficult access to mainland due to geographical (high mountains, remote islands) or climatic (tundra, permanently frozen polar areas) features.

\section{The Leading Role of Industry in the Economy of The Nakhchivan Autonomous Republic}

Rational arrangement of the industry throughout the country is one of the vital means in providing national economy and social perspective as being the main feature of territory arrangement of productive forces. This process as a rule begins from the arrangement of industrial establishments all processes are implemented on the basis of economic productivity. When selecting of the regions to place of this and other establishments and also grounding it one should not satisfy with its expected local productivity. In the same time the role of the very industrial object in new repeated production, its contribution to this process and efficiency entirely in the country should be considered main. Along with this in placing industrial establishments, concretely also non-economic profits, political, national security, defense of country and other factors by all means must be considered. Even Azerbaijan after gaining its independence the actuality of manpower and industrial establishments placement according to the territory not only lost its effect but also earned a very serious form. Together with these common demands in industrial production placement the below stated principles grounded scientifically should be observed:

1. Bringing industrial production nearer raw material sources and consumption regions. By following these principles natural resources can easily be drawn into economy circulation rationally and in its turn puts resistance in carrying raw materials to far distances.

2. Placing of industrial production equally according to the territory of country. Observing these principles in placing industrial production provides the balance of social-economic development of the economic regions of the country and settles the issue of rational use of natural resources and manpower resources respectively and also it prevents non-organized migration of population and so on.

3. Productive labour division among economic regions and complex development of their economy. Guided these principles main determines their directions of specializing according to industrial production together with complex development of economic regions.

4. Internationalizing of economy and its necessity of participation in the international labour division. Realizing of this principle is provided with economic sovereignty, integration to the world economic system in the atmosphere of open economy, creation of establishments and national ownership.

5. Defense of the country from foreign aggression and protection of environment. Observation of this principle has become a very actual question for our republic that newly gained her independence. (T.A. Huseynov, 2000)

As being long complicated process of placement of industry, placement of establishments, forming industrial junctions and centers cover three stages in mutual relations of forming industrial complexes. At present there are various views about the significance of industrial junctions in the economic literatures. As it has been stated by 
some foreign economists and geography critics, the base of economic junctions is comprised by natural condition and unity of economy elements. The popular scientists of geography Richard Hartsharn, K. Cons Kloran, Russel Smith, Fransua Rern are included to the supporters of this idea.

Russian-Soviet scientists P. M. Alampiriyev, A. Y. Probst, E. B. Alayev, L. Y. Ziman, Y. Sh. Saushkin and others were intensively busy with the essence of the industrial junctions, investigation of theoretical and methodological basis of them.

Azerbaijani scientists A. A. Nadirov, A. Kh. Nuriyev, S. K. Huseynov and others have shared much place to industrial junctions investigation in their works.

There are common methodological basis in the views of the Azerbaijan economists about the essence of the industrial junctions. According to their views the industrial junctions are industrial fields with a leading role in every territorial- industrial complex (Sumgayit, Mingachevir, Shirvan, Nakhchivan, Ganja, Shaky, Lankaran and so on). Considering this one can find no serious difference in their views.

Forming industrial junctions and its development in modern period has own specific principles. Among them the following items may be called:

1. Planned development and placement of industrial junctions on the basis of scientific-progress and increase of productivity.

2. Social division of labour providing expedient specialization of production, economic relation, cooperation and territory forming.

3. Raw material sources of industry and drawing to products consumers.

4. Placing of industry but considering integration and labour division.

5. Efficient forming of industrial cooperation in the economic development of the regions and so on. (A. A. Nadirov, S. K. Huseynov, 1984)

Science and the factor as a scientific service play an important role in forming of industrial junction and its development. Scientific-technical progress gives an opportunity in intensifying of products output and diminishes of manual labour percentage share, engages new natural resources to the production circulation, creates good atmosphere in settlement of new areas and also reduces technological affects to environment.

State policy plays a great role in securing social-economic development, out of which in providing the promotion of industry.

Current and strategic goals, objectives put ahead by State and also a State policy as a part in realizing them bases on correct directions of social-economic development. The social-economic development policy of State consists of different elements; one of the vital directions of social-economic policy as-finance, monetary-credit, social, agrarian, structural, foreign economic policy, taxes, policy of ecology and etc. comprises regional development policy. (A. Kh. Nuriyev, 2004)

In connection with a successful solution of regional policy a direct state management of economy is implemented more than.

One of the regional policy realization objectives is the method of the purposed program-prognosis.

While preparing the program the current social-economic condition of the region is analyzed and assessed. Social-economic condition of the region and result of this condition for the region are noted and the most priority problems to be solved are selected. The condition of natural resources and environment are assessed. The prognosis model of the program is worked out. Every measure included and considered in the program is valued according to quantitative and qualitative indicators and economic efficiency of it is calculated. (N. I. Larina, A. A. Kselnikov, 1998)

One of the most important forms of the regional policy in the countries passing to market economy is the creation of free economic zones. The free zones of specific geographical areas where customs concessions act in industry, trade, tax play a great role in foreign and local investment, in use of modern technologies, management experience and in cadre choice and above all in opening new work places.

The world practice shows that free economic zones give opportunity to the development of foreign economic relations, generally in investing foreign and local capitals to different regions of the country and also in engaging new technology and management experience, in its turn it impact to economic and social development positively. (A. I. Pogorlensky, 2000) 
In a word regional, social-economic policy of state should put perspective goals in front of regions and economy fields development, should determine very urgent objectives in arriving at these aims, should work out management and regulation mechanism capable to fulfill the task from the interest of regions point of view and finally should stimulate its implementation.

According to the "State Program (2004-2008) on social-economic development of the regions" signed by the President of State, Ilham Aliyev on 11 February 2004 new industrial fields have been established in the Nakhchivan Autonomous Republic and the output of industrial production went on increasingly raise.

On the basis of successful implementation of the duties put ahead in the program possible structure innovation was held in the regions, entrepreneurship activity was considerably widened, suitable investment atmosphere was formed and modern type of industrial establishments were created. So that, within 2004-2008 years 147 industrial establishments were created in the autonomous republic or they were reestablished on the basis of new technology.

The rate of industrial product increased 6,4 times in 2008 compared with the result of 2004. All these once again prove the successful implementation of the State Program put in front of the Nakhchivan Autonomous Republic industry development.

According to the economic independent strategy determined by Heydar Aliyev, national leader of the Azerbaijan population and the strategy continued by Ilham Aliyev, head of state, the held structure reforms, integration of economy into international economic relations and economy relations has caused the dynamic growth of social-economy in the Nakhchivan Autonomous Republic too and in its part created a reliable base to the development of all economic fields.

As a result of which the macroeconomic indicators in the autonomous republic developed dynamically by years. All these have been pictured in the below shown table.

Table 1. Macroeconomic indicators of the Nakhchivan Autonomous Republic for 2009-2010

\begin{tabular}{lccc}
\hline \multirow{2}{*}{ Macroeconomic indicators (in thousand manats) } & \multicolumn{2}{c}{ Years } \\
\cline { 2 - 4 } & $\mathbf{2 0 0 9}$ & $\mathbf{2 0 1 0}$ & analogical comparison in \% (percent) \\
\hline Gross domestic product & 973649,3 & 1171305,7 & $116,6^{*}$ \\
& & & 118,4 \\
Gross domestic product per capita, in manat & 2434,7 & 2882,9 & 118,6 \\
in the USA dollar & 3029,4 & 3591,9 & $144,4^{*}$ \\
Total capacity of industrial production & 212469,1 & 318564,8 & 121,8 \\
Investments put on main capital & 411522,0 & 501105,5 & $113,3^{*}$ \\
Total product of agriculture & 185117,2 & 247126,6 & 114,7 \\
Freight transportation in transport sector, one thousand ton & 9723,0 & 11152,7 & 117,5 \\
Rate of information and communication services & 31119,9 & 36579,3 & $119,9^{*}$ \\
Retail goods turnover & 484777,5 & 616454,4 & $117,8^{*}$ \\
Paid service to population & 87255,8 & 107242,3 & 117,2 \\
Foreign trade turnover, one thousand USA dollar & 220046,5 & 257933,3 & 188,5 \\
including & & & 42,9 \\
total rate of export & 112287,2 & 211714,4 & 110,3 \\
total rate of import & 107759,3 & 46218,9 & 108,6 \\
Income of population & 913371,6 & 1007483,6 & 111,1 \\
Incomes per capita, in manat & 2284,0 & 2479,9 & \\
Average monthly salary (wage) calculated per worker, in manat & 272,3 & 302,6 & \\
\hline
\end{tabular}

According to the table report analysis the rate of gross domestic product in the autonomous republic raised 16,6 per cent in 2010 compared with 2009, the total rate of industrial product increased 14,4 per cent, the total product of agriculture uprose 13,3 per cent and the investments put to main capital made up 21,8 per cent rise.

\section{The Most Important Strategic Duty of The Nakhchivan Autonomous Republic in the Field of Economy}

In general, one can arrive at a conclusion after carried out analysis and investigations that for the purpose to increase industrial potential in the autonomous republic the taken systematic measures are resulted fruitfully 
Today the most important strategic duty in front of the autonomous republic must base on the efficient use of natural resources in local production, export of products to foreign market, creation of condition for the competition sustainability

The future perspective of industrial production complex in the Nakhchivan Autonomous Republic must base on local rich mineral excavation reserves either fully and perfectly, dependence of local industry from the delivered raw materials must be reduced maximally.

The territory of the autonomous republic is rich with different minerals and manifestations as: molybdenum, copper, copper-molybdenum, copper-polymetal, spray-arsenic, mercury cobalt, wolfram, titan, gold, lead, manganese, zinc, rock-salt, dolomite, bauxite, phosphorite, sulphur, travertine, black marble, cement raw material, construction materials etc. Also there are more than 200 mineral and termal springs of healing importance as: Sirab, Badamly, Daridagh, Vaykhir, Nahajir, Gahab, Gizilburun, Jahry, Suramly and others. (S. Y. Babayev, 1999)

As a result of geological-exploration works carried out in the territory of the Nakhchivan Autonomous Republic a great deal of building material deposits of mineral origin were discovered and learned. In order to make effective use of different kind of rich minerals of Nakhchivan it is possible to establish small volume metal purifying, metal smelting, cast iron melting on the basis of local raw material and also new establishments connected with steel production.

It is already high time to use of rich chemical raw material reserves ( rock salt, dolomit, phosphorite, sulphur etc.) in Nakhchivan AR in developing chemical industry more widely. Thus, natural condition and natural richness of Nakhchivan gives a chance to say that this region is having a great social- economic development possibility after assessing the existing potential from economic points of view.

The world practice shows that regardless of the level of social- economic development and national features the provision of sustainable economic progress not only depends on domestic means but also is possible on the basis of home and foreign factors unanimity. Total social, economic and juridical conditions of investment activity of industrial fields acting in the area of country is specified by the law "On investment activity" of the Republic of Azerbaijan (On Investment activity The Law of the Republic of Azerbaijan, 1995).

The very law was attributed to all kind of investments focused to the economy of the country, also it was forwarded to the social-economic base of the country and in the same time to reinforcing international economic collaboration and integration promotion and despite of property form it ensures equal rights of all investors.

According to the wide spread world experience several joint cooperation forms are existing in implementing investment activity: such as: consent on profit division regardless of share of participation, service consent, cooperation forms and concession through joint establishment creation.

Classical self finance form in the industrially developed countries of the world is said to be the interest rate of establishment and special allocations formed on the basic funds shares for amortization, money allocation from the sale of securities and bank credits.

No doubt that foreign investments are much more important for the countries who newly gained their independence. Because the reestablishment of economy in these countries and its extension demands a great amount of capital investment. But it is impossible to realize this process in the countries who newly gained independence and in market economy formed regions especially there where there is investment insufficiency by means of domestic opportunities. Considering this, to develop economy by the help of government demands foreign capital investment together with domestic investments. (A. L. Aliyev, 2000)

Thus, in order to develop economy in Nakhchivan Autonomous Republic in the nearest future foreign capital investment is very important side by side with internal investment and for this it is offered to prefer ownership activity together with foreign investors.

To provide the development of industrial fields in Nakhchivan Autonomous Republic and to restore the activity of the industrial establishments existed here before is the question to settle in the perspective. Light and food industry in Nakhchivan economic region occupies a leading place. The total parentage share of them in total industrial product is about $75 \%$. At present "Gamigaya Barakat Food Products" LTD, "Jahan Holding" Commercial Company Union, "Badamly Mineral Waters Works" LTD, "Sirab" OJS (Open Joint Stock), "Lazzat Food Industry" LTD, "Nakhchivan Brick" OJS, "Underwear knitted goods factory" OJS , "'Sewing" OJS, "Glass works" OJS, "Carpet" OJS, "Grain and rolls and buns" OJS and other establishments are acting in the Nakhchivan Autonomous Republic. But some of these establishments don't work due to their project power . Therefore the existing problems solution in this field is said to be more urgent on the agenda. Joint use of home 
and foreign investments for the development of the economy of the Nakhchivan Autonomous Republic is necessary to create a good atmosphere in all fields for the foreign businessmen, ownerships, investors to put their capitals on the bases of mutual interest.

In order to supply the demand of the population of the Nakhchivan Autonomous Republic on the basis of local food products completely, we think that, it is important to widen auxiliary economies and with this to lessen the dependence from abroad and to provide the production with local raw material must be on the agenda as the most important question.

For us in the perspective development of industrial complex of the Nakhchivan Autonomous Republic the correct way of usage from agriculture, transport promotion and manpower must be considered without any delay.

For the purpose to provide more efficient use of current potential of the regions a special decree was confirmed on April 14, 2009 by the President on "State Program on social-economic development for 2009-2013 of the regions of the Republic of Azerbaijan". The most advanced priorities connected with the development of the Nakhchivan Autonomous Republic were determined in the new social-economic development program.

The below stated issues were determined in the State Program: construction of new industrial fields in the Nakhchivan Autonomous Republic, restoration of mine-industry establishments activity and creation of new establishments, restoration of new OJS existing in the area of the Nakhchivan Autonomous Republic and their furthermore development, creation of various food products industry, exploration of new construction material beds and investigation, restoration of vineyards, fruit gardens, ploughing areas and widening them, restoration of silkworm breeding and developing, widening poultry farms production, developing of fish industry (Upon the Decree №80 April 14, 2009).

According to the State Program in a short time these below indicated establishments were created and put in use in the Nakhchivan Autonomous Republic. They are: Nakhchivan Cement works, Fishery in Garabaghlar village of Kangarly district, Fishery in Garababa village of Shahbuz district, "Karimbayly" Poultry Farm in Babak district, "Aylis" Poultry Farm in Ordubad district, "Kirna" Poultry Farm in Julfa district and some other establishments. We are hopeful furthermore works according to the State Program will be more scientifically and efficiently in industrial direction in Nakhchivan Autonomous Republic and the gained results will be in power to supply the demands of population successfully.

\section{Conclusion}

On the basis of the carried investigation we come to the conclusion that the natural condition of the Nakhchivan Autonomous Republic, its geographical position, geopolitical situation, rich natural resources, existence of enough manpower, high level personnel potential, the existing social and production infrastructure create objective atmosphere in rapid development of the industrial fields. The development inclinations of the industry and its features in the Nakhchivan Autonomous Republic are analyzed, creation of new industrial establishment opportunities on the basis of local raw material, ways of its financial maintenance strengthening and perspective growth directions are stated. The analysis show that industry has a leading role in the economy of the Nakhchivan Autonomous Republic.

The model of development of economy, in particular, industry in the example of the Nakhchivan Autonomous Republic can be applied for the remote regions which are exclaves or locations with difficult access to mainland due to geographical (high mountains, remote islands) or climatic (tundra, permanently frozen polar areas) features.

\section{References}

Ahmadov, N. H. (2005). Nakhchivan economy on the ways of development. Monograph. Baku: Elm.

Ahmadov, N. H. (2008). Problems of Nakhchivan economy: economic growth, dynamical development. Monograph. Baku: Sabah.

Aliyev, A. L. (2000). The necessity of joint establishments with foreign investment creation. In the book of key inclinations (collection of articles) of social- economy development of Azerbaijan in modern period. (9th edition) Baku: Elm.

Babayev, S. Y. (1999). Geography of Nakhchivan Autonomous Republic. Baku: Elm, 298.

Huseynov, T. A. (2000). Industrial economy. Baku: East-West.

Larina, N. I., \& Kselnikov, A. A. (1998). Regional policy in the countries of market economy. Moscow: Economy. 
Nadirov, A. A., \& Huseynov, S. K. (1984). Development of regional-industrial complexes. Baku: Elm.

Nakhchivan Autonomous Republic. Nakhchivan encyclopaedia. (2002). National Academy of Sciences of Azerbaijan. Baku.

Nakhchivan encyclopaedia (2005). In two volumes. Nakhchivan Department of the National Academy of Sciences of Azerbaijan. Second edition. 2nd volume. Nakhchivan.

Nakhchivan encyclopaedia. (2005). In two volumes. Nakhchivan Department of the National Academy of Sciences of Azerbaijan. Second edition. 1st volume. Nakhchivan.

Nuriyev, A. Kh. (2004). Regional policy and management. Baku: Elm.

On Investment activity The Law of the Republic of Azerbaijan. (1995). January 13, No 952.

Pogorlensky, A. I. (2000). Economy of foreign countries. SPB: Fenix.

The President of the Republic of Azerbaijan. (2009). State Program on social-economic development for 2009-2013 of the regions of the Republic of Azerbaijan upon the Decree No 80 April 14. 